\title{
(6) OPEN ACCESS \\ Decomposing the association between the amount of exposure and the frequency of self-reported involvement in a road crash
}

\author{
Eladio Jiménez-Mejías, ${ }^{1,2}$ Pablo Lardelli-Claret, ${ }^{1,2}$ José Juan Jiménez-Moleón, ${ }^{1,2}$ \\ Carmen Amezcua-Prieto, ${ }^{1,2}$ José Pulido Manzanero, ${ }^{2,3}$ Juan de Dios Luna-del-Castillo ${ }^{2,4}$
}

\begin{abstract}
-Additional supplementary data are published online only. To view these files please visit the journal online (http://dx.doi org/10.1136/injuryprev-2012 040467).
\end{abstract}

${ }^{1}$ Department of Preventive Medicine and Public Health, School of Medicine, University of Granada, Granada, Spain ${ }^{2}$ Centros de Investigación Biomédica en Red de Epidemiología y Salud Pública (CIBERESP), Spain

${ }^{3}$ Centro Nacional de Epidemiología, Instituto de Salud Carlos III, Madrid, Spain ${ }^{4}$ Department of Biostatistics, School of Medicine, University of Granada, Granada, Spain

\section{Correspondence to}

Dr Eladio Jiménez Mejías, Departamento de Medicina Preventiva y Salud Pública, Facultad de Medicina Universidad de Granada, Avda. de Madrid 11, Granada 18012, Spain;

eladiojimenez@ugr.es

Accepted 12 October 2012 Published Online First

5 November 2012

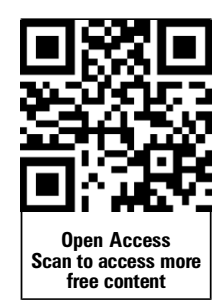

\section{ABSTRACT}

We tried to obtain preliminary evidence to test the hypothesis that the association between driving exposure and the frequency of reporting a road crash can be decomposed into two paths: direct and indirect (mediated by risky driving patterns). In a cross-sectional study carried out between 2007 and 2010, a sample of 1114 car drivers who were students at the University of Granada completed a questionnaire with items about driving exposure during the previous year, risk-related driving circumstances and involvement in road crashes. We applied the decomposition procedure proposed by Buis for logit models. The indirect path showed a strong dose-response relationship with the frequency of reporting a road crash, whereas the direct path did not. The decomposition procedure was able to identify the indirect path as the main explanatory mechanism for the association between exposure and the frequency of reporting a road crash.

\section{INTRODUCTION}

Causal associations between exposures and outcomes may be direct or indirect (ie, mediated through the effect of intermediate variables). For instance, it can be hypothesised that the wellknown relationship between the amount of exposure as a car driver and the risk of involvement in a road crash $^{1-3}$ can be broken down into direct and indirect paths (figure 1). In the former, the amount of exposure leads to a higher risk of involvement in a crash as a result of increasing time at risk. In the latter, the link between exposure and road crashes is mediated by an increase in the frequency of well known risky driving patterns. ${ }^{4-6}$ This path implies that an increase in exposure leads to a higher frequency of involvement in circumstances, such as driving at night or at higher speed. Previous studies support this relationship. 48

We found no previous studies designed to test the above hypothesis, and therefore, tried to obtain preliminary empirical evidence to support or refute it. We applied the analytic approach recently proposed by Buis, ${ }^{9}$ (an extension of the decomposition method described by Eriksson et $a l^{10}$ for logit models) to a cross-sectional study of university students that explored driving exposure as car drivers ( $\mathrm{km} /$ year driven), the involvement in risky driving patterns and the frequency of reporting a road crash. Our aim was to decompose the association between the amount of exposure and the frequency of reporting a road crash in a direct path and in an indirect path (mediated through risky driving patterns).

\section{MATERIALS AND METHODS}

The eligible population for this cross-sectional study comprised all students enrolled in any of the courses offered by the department of preventive medicine and public health at the University of Granada (southern Spain) during the academic years 2007/2008, 2008/2009 and 2009/2010, and who attended classes during at least the first 2 weeks of any given course. After informing them about the study aims, the course instructors asked all students to complete a brief self-administered questionnaire. A total of 1114 students who completed the questionnaire and who stated they had driven a passenger car during the previous year comprised our final sample.

The questionnaire (shown in the web Appendix) was developed by an expert panel after an extensive review of previous instruments. ${ }^{11}$ Among other variables, it explored driving exposure $(\mathrm{km} /$ year driven in the previous year) originally stratified in eight categories ( $<500 \mathrm{~km}, 500-999,1000-4999$, 5000-9999, 10 000-19 999, 20 000-29 999, 30000 $50000,>50000)$ and finally categorised in four strata (<500 km/year, 500-999, 1000-4999 and $>5000$ ), driving patterns measured as involvement or not during the preceding month in 22 driving circumstances potentially related with the risk of involvement in a road crash (see the web Appendix for a detailed description of each circumstance) and involvement in a road crash that did or did not result in injuries during the previous year. All these circumstances have been associated with varying degrees with an increased risk of having an accident, according to earlier research. ${ }^{11}$

Analysis: We used the method proposed by Buis, ${ }^{9}$ a generalisation of the original decomposition method developed by Erikson et al. ${ }^{10}$ This method decomposes the total association between a categorical, discrete or continuous exposure variable, and an outcome in a direct effect and an indirect effect. In our case, we applied the Buis procedure to a logit model in which the outcome was the log (odds) of reporting involvement in a road crash during the previous year, exposure was the number of kilometres driven in the previous year (stratified in four levels), and the intermediate variable was the number of driving circumstances reported by each driver, included in the model as a continuous variable. The model also included sex, age and years in possession of 


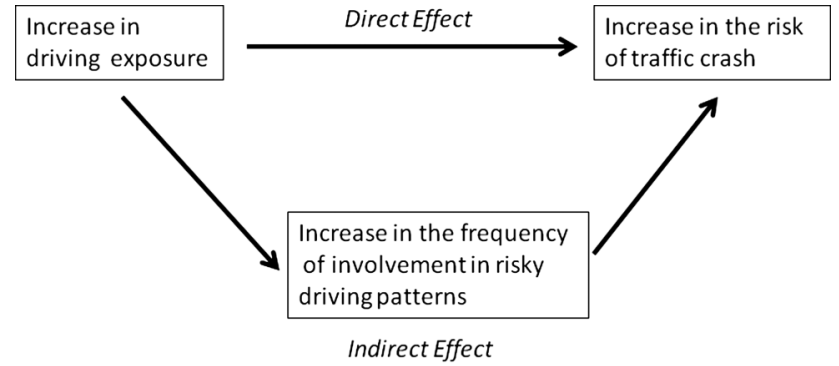

Figure 1 The two possible causal paths to explain the association between driving exposure and the risk of traffic crash.

a driving license as potential confounders. The inclusion of confounders in the decomposition model is an additional advantage of the Buis extension of the original decomposition procedure by Eriksson et al ${ }^{10}$ The model allows us to decompose the total association between each exposure level (using the lowest level as the reference) and the frequency of reporting a road crash in the previous year into two components: direct and indirect (mediated by the number of driving circumstances reported by each driver as shown in figure 1). Equations obtained from ldecomp command applied to a logit model produce three OR estimations for each exposure level: OR for total effect (direct plus indirect paths); OR for the direct path and $\mathrm{OR}$ for the indirect path (mediated through risky driving patterns). As we are using a multiplicative model, it can be shown that $\mathrm{OR}$ (direct) $\times \mathrm{OR}$ (indirect) $=\mathrm{OR}$ (total). It is also possible to use the original coefficients of the model to express the above decomposition in additive terms, to determine the percentage relative contribution of each path to the total association. Bootstrapping (1000 iterations) was used to obtain CIs for the estimated ORs. The Buis method was implemented with the ldecomp package from Stata 12 (StataCorp, 2011). ${ }^{9} 12$

\section{RESULTS}

The main characteristics of the sample of car drivers, stratified across the four exposure categories, are shown in the web table. Table 1 shows the OR obtained for the total, indirect (mediated by driving circumstances) and direct (not mediated by driving circumstances) association of each level of driving exposure with the frequency of reporting a road crash, compared with the lowest level of exposure $(<500 \mathrm{~km} /$ year). A clear positive association between exposure and reporting a road crash appears for exposures equal to or higher than $1000 \mathrm{~km} /$ year. When this association is decomposed, the indirect path shows a clear dose-response relationship between exposure and reporting a road crash. However, the direct path does not show a clear pattern of association.

Table 1 also shows the relative contribution (in percentage) of each path to the total association between driving exposure and the frequency of reporting a road crash. For the second exposure level (500-999 km/year), the direction of the direct and indirect associations is opposite, a result that explains
Table 2 Predicted and counterfactual frequencies of reporting a road crash for each level of exposure among students of the University of Granada, Spain, 2007-2010*

\begin{tabular}{|c|c|c|c|c|}
\hline \multirow{2}{*}{$\begin{array}{l}\text { Number of risky driving } \\
\text { circumstances corresponding } \\
\text { to an exposure of ... }\end{array}$} & \multicolumn{4}{|c|}{ Categories of driving exposure } \\
\hline & $\begin{array}{l}<500 \\
\mathrm{~km} / \text { year }\end{array}$ & $\begin{array}{l}\text { 500-999 } \\
\text { km/year }\end{array}$ & $\begin{array}{l}\text { 1000-4999 } \\
\text { km/year }\end{array}$ & $\begin{array}{l}\geq 5000 \\
\mathrm{~km} / \text { year }\end{array}$ \\
\hline$<500$ km/year & 0.022 & 0.011 & 0.045 & 0.038 \\
\hline 500-999 km/year & 0.030 & 0.015 & 0.062 & 0.052 \\
\hline $1000-4999$ km/year & 0.038 & 0.020 & 0.077 & 0.065 \\
\hline$\geq 5000 \mathrm{~km} /$ year & 0.050 & 0.026 & 0.099 & 0.084 \\
\hline
\end{tabular}

*Diagonal values in the table (shaded) show the frequency of reporting a road crash predicted by the model for each exposure category, considering the factual (real) number of driving circumstances corresponding to this category. Off-diagonal values are counterfactual values: these show the frequency of reporting a road crash that would have been obtained for each level of exposure (columns) with the number of risky driving circumstances corresponding to the other exposure levels (rows).

the 'negative' percentage contribution of the indirect path to the total association. The contribution of the direct path to the total association between driving exposure and reporting a road crash decreases as exposure level increases.

Table 2 shows the factual and counterfactual frequencies of reporting a road crash for each exposure level. Diagonal values in the table (shaded) show the frequency of reporting a road crash predicted by the model for each exposure category, considering the factual (real) number of driving circumstances corresponding to this category (ie, the total association between driving exposure and the frequency of reporting a road crash). These frequencies were $2.2 \%$ for $<500 \mathrm{~km} /$ year, $1.5 \%$ for 500 $999,7.7 \%$ for $1000-4999$ and $8.4 \%$ for $\geq 5000 \mathrm{~km} /$ year. The offdiagonal values are counterfactual values that show the frequency of reporting a road crash that would have been obtained for each level of exposure (columns) with the risky driving circumstances corresponding to the other exposure levels (rows). Reading the table row by row shows the expected variability in the frequency of reporting a road crash as a result of the direct association with exposure (unrelated with changes in the number of driving circumstances). For example, for the pattern of driving circumstances corresponding to an exposure of $<500 \mathrm{~km} /$ year, drivers with exposures of $<500,500-999$, $1000-4999$ and $\geq 5000 \mathrm{~km} /$ year would have reported involvement in a road crash at a frequency of $2.2 \%$ (the real value), $1.1 \%, 4.5 \%$ and $3.8 \%$, respectively.

Reading the table column by column shows, for a given exposure level (column), the changes in the frequency of reporting a road crash related to the number of risky driving circumstances corresponding to the other exposure levels. These changes illustrate the variability in the reported frequency of road crashes resulting only from the indirect association with exposure. For example, for drivers with exposures $<500 \mathrm{~km} /$ year and the risky driving patterns corresponding to increasing exposure levels, their expected frequencies of reporting a road crash would have been $2.2 \%$ (the real value), $3.0 \%, 3.8 \%$ and

Table 1 Total, Direct and indirect associations between the amount of exposure and reported involvement in a road crash among students at the University of Granada, Spain, 2007-2010

\begin{tabular}{|c|c|c|c|c|c|c|c|c|}
\hline \multirow[b]{2}{*}{ Exposure (Reference: <500 km/year) } & \multicolumn{2}{|c|}{ Total } & \multicolumn{3}{|c|}{ Direct } & \multicolumn{3}{|c|}{ Indirect (mediated through risky driving patterns) } \\
\hline & $\mathbf{O R}$ & $95 \% \mathrm{Cl}$ & $\mathbf{O R}$ & $95 \% \mathrm{Cl}$ & $\%$ of the total association* & $\mathbf{O R}$ & $95 \% \mathrm{CI}$ & $\%$ Of the total association* \\
\hline 500-999 km/year & 0.70 & 0.17 to 2.82 & 0.50 & 0.12 to 2.02 & 191.64 & 1.39 & 1.10 to 1.75 & -91.64 \\
\hline$\geq 5000 \mathrm{~km} /$ year & 4.14 & 1.59 to 10.83 & 1.76 & 0.60 to 5.21 & 39.87 & 2.35 & 1.40 to 3.95 & 60.13 \\
\hline
\end{tabular}

*These columns report the proportion of the association attributable to the direct and indirect paths assuming a value of $100 \%$ for the total association. 
$5.0 \%$. For a given column, the indirect association shows a clear dose-response relationship for increasing exposure level, whereas this is not the case for the direct associations (rows): the counterfactual frequencies of reporting a road crash are lowest for the second exposure level, and highest for the third level.

\section{DISCUSSION}

Regarding our initial hypothesis that two different paths can be identified to relate the amount of exposure to the frequency of reporting a road crash, our results suggest that the relationship mediated through the association between exposure and involvement in risky driving patterns is clearly more important than the relationship mediated simply through the increase in time at risk. Although many studies have reported the crude and adjusted associations between the risk of a road crash and the amount of exposure, ${ }^{11314}$ or certain driving patterns, such as those explored in our questionnaire, ${ }^{15} 16$ to our knowledge, no previous studies have applied an appropriate decomposition method to test our hypothesis.

Our study should be viewed as an initial attempt to shed light on our decomposition hypothesis. Its cross-sectional nature makes it impossible to demonstrate causal associations between the variables explored here. In fact, inverse causality cannot be ruled out because the period in which risky driving circumstances were explored comprised only the month prior to the interview, whereas exposure and road crashes were explored for the previous year. Our results may also be affected by information bias: although the questionnaire used to explore driving patterns has acceptable convergent and criterion validity $^{17}$ this source of bias cannot be ruled out entirely. Furthermore, we used a rather simple index to measure the indirect effect, and did not consider the different roles of each specific risk-related circumstance. Regarding external validity, our results were obtained for a population of mainly young, inexperienced and predominantly female drivers-a demographic composition typical among students in health sciences degree programmes at Spanish universities. ${ }^{18}$ There is no reason to suspect that the associations found in this population would differ greatly in other subgroups of drivers, and all our estimates were adjusted by gender, age and years in possession of a driving license (a correlate of experience). ${ }^{19} 20$ These caveats, notwithstanding, the Buis procedure allows the inclusion of other adjusting variables not considered in the present study, such as variables for driving inexperience. Further studies in other populations will, therefore, be needed to confirm the consistency of our results. In addition, the same analytical approach as we used here should be applied to data from cohorts of drivers.

\section{What is already known on this subject}

Causal associations between amount of exposure $(\mathrm{km} / \mathrm{year})$ as a car driver, and the risk of involvement in a road crash may be direct or indirect (ie, mediated through the effect of intermediate variables). In direct associations, the amount of exposure leads to a higher risk of involvement in a crash as a result of increasing time at risk. In indirect associations, the relationship between exposure and road crashes is mediated by an increase in the frequency of well-known risky driving patterns.

\section{What this study adds}

- Although many studies have reported the crude and adjusted associations between the risk of a road crash and the amount of exposure or certain driving patterns, no previous studies have applied an appropriate decomposition method to test this hypothesis. Our results suggest that the relationship mediated through the association between exposure and involvement in risky driving patterns is clearly more important than the relationship mediated simply through the increase in time at risk.

\section{Key points}

- The relationship between the amount of exposure as a car driver, and the risk of involvement in a road crash is well known.

- The association between driving exposure, and the frequency of reporting a road crash, can be decomposed into two paths: direct and indirect (mediated by risky driving patterns).

- The relationship mediated through the association between exposure and involvement in risky driving patterns is clearly more important than the relationship mediated simply through the increase in time at risk.

Acknowledgements We thank K Shashok for improving the use of English in the manuscript.

Contributors EJM: data acquisition, analysis and interpretation, drafting the article and final revision. PLC: conception and design the study, drafting the article and final revision. JJJM: critical review and final approval of the manuscript. CAP: data acquisition, analysis and interpretation. JPM: data interpretation, drafting the article and final revision. JdDLdC: data analysis and interpretation, critical review and final approval of the manuscript.

Funding This study was financed by the Regional Government of Andalucía (Proyecto de Excelencia P06-CTS-01524), by FEDER funds (EU) and by the Centro de Investigación Biomédica en Red de Epidemiología y Salud Pública (CIBERESP).

Competing interests None.

Ethics approval Bioethics Committee School of Medicine University of Granada

Provenance and peer review Not commissioned; externally peer reviewed.

Open Access This is an Open Access article distributed in accordance with the Creative Commons Attribution Non Commercial (CC BY-NC 3.0) license, which permits others to distribute, remix, adapt, build upon this work non-commercially, and license their derivative works on different terms, provided the original work is properly cited and the use is non-commercial. See: http://creativecommons.org/ licenses/by-nc/3.0/

\section{REFERENCES}

1. Factor $\mathbf{R}$, Mahalel D, Yair $\mathrm{G}$. Inter-group differences in road-traffic crash involvement. Accid Anal Prev 2007;40:2000-7.

2. Laapotti S, Keskinen $\mathrm{E}$, Hatakka $\mathrm{K}$, et al. Driving circumstances and accidents among novice drivers. Traffic Inj Prev 2006;7:232-7.

3. Lucidi F, Giannini AM, Sgalla R, et al. Young novice driver subtypes: relationship to driving violations, errors and lapses. Accid Anal Prev 2010;42:1689-96.

4. Boufous S, Ivers R, Senserrick T, et al. Accuracy of self-report of on road crashes and traffic offences in a cohort of young drivers: the DRIVE study. Inj Prev 2010;16:275-7.

5. Ivers R, Senserrick T, Boufous $S$, et al. Novice drivers's risky behaviour, risk perception, and crash risk: findings from the DRIVE study. Am J Public Health 2009;99:1638-44. 
6. Nabi H, Salmi LR, Lafont S, et al. Attitudes associated with behavioral predictors of serious road traffic crashes: result from the GAZEL cohort. Inj Prev 2007;13:26-31.

7. Cestac J, Paran F, Delhomme P. Young drivers' sensation seeking, subjective norms, and perceived and perceived behavioral control and their roles in predicting intention: how risk-taking motivations evolve with gender and driving experience. Saf Sci 2011:49:424-32

8. Fernandes R, Hatfield J, Soames J. A systematic investigation of the differential predictors for speeding, drink-driving, driving while fatigued, and not wearing a seat belt. Transport Res F Traffic Psychol Behav 2010;13:179-96.

9. Buis ML. Direct and indirect effects in a logit model. The Stata J 2010;10:1-19

10. Eriksson R, Goldthorpe $\mathrm{JH}$, Jackson $\mathrm{M}$, et al. On class differentials in educational attainment. Proc Natl Acad Sci 2005;102:9730-33.

11. Jiménez Mejías $\mathbf{E}$, Lardelli Claret $P$, Amezcua Prieto $C$, et al. A review of questionnaires exploring drive's exposure and risk factors in road crashes (Spanish). An Sist Sanit Nav 2011;34:433-52.

12. StataCorp. Stata Statistical Software: Release 11.0. College Station, TX: Stata Corporation; 2009.

13. Amoros E, Martin JL, Laumon B. Comparison of road crashes incidence and severity between some French counties. Accid Anal Prev 2003;35: 537-47.
14. Laberge-Nadeau C, Maag U, Bourbeau R. The effects of age and experience on accidents with injuries: should the licensing age be raised? Accid Anal Prev 1992:24:107-16

15. Machin MA, Sankey KS. Relationships between young drivers' personality characteristics, risk perceptions, and driving behaviour. Accid Anal Prev 2008; 40:541-7.

16. Nallet N, Bernard M, Chiron M. Self-reported road traffic violations in France and how they have changed since 1983. Accid Anal Prev 2010;42:1302-9.

17. Jiménez-Mejías E, Luna del Castillo JD, Amezcua-Prieto C, et al. Design and validation of a questionnaire exploring risky-driving patterns in young drivers (Spanish). Rev Esp Salud Pub 2012;86:71-84.

18. Spanish Institute of Statistics. Estadística de la enseñanza universitaria en España. Alumnado matriculado en estudios de primer y segundo ciclo por Universidad, sexo, ciclos y ramas. Curso. 2009-2010. (http://www.ine.es// (accessed 11 Apr 2012)

19. Mccartt AT, Mayhew DR, Braitman KA, et al. Effects of age and experience on young driver crashes: review of recent literature. Traffic Inj Prev 2009;10:209-19.

20. Özkan T, Lajunen T. What causes the differences in driving between young men and women? The effects of gender roles and sex on young drivers' driving behaviour and self-assessment of skills. Transport Res F Traffic Psychol Behav 2006;9:269-77.

\section{Texting while driving linked with other risky behaviours}

A recent study by CDC shows that texting while driving among US high school students is linked with drinking and driving, or riding with someone who has been drinking. This study in paediatrics is hardly surprising but worth emphasising. Of special importance is the key finding that nearly half of them text or email while driving, and those who do so are nearly twice as likely to ride with a driver who has been drinking, and five times as likely to drink and drive, than students who do not text while driving. Most states have laws to limit texting or cell phone use while driving, but there are few evaluations of these laws and, thus, no evidence that the laws reduce crashes. The CDC release emphasises the role parents can have in curtailing these dangerous behaviours.

\section{CAPT child safety week focuses on poisoning}

A popular approach to poison prevention in the UK (and, I assume, much of Europe) was the focus of this year's Child Safety Week sponsored by Child Accident Prevention Trust (CAPT). To drive home to parents the dangers of childhood poisoning, and the risks lurking under their kitchen sinks, CAPT advocated that parents taste Bitrex the most bitter substance on Earth. (I use it to discourage squirrels from eating my garbage and I can testify to how bitter it is!) To combat poisoning, Bitrex is added to household products that young children might drink. It acts as a third line of defence against poisoning (after storing products out of reach and childresistant packaging). CAPT suggests you see for yourself by checking out a Youtube video of parents taking the Big Taste test.

http://www.youtube.com/watch?v=4kugKYHZOTU

http://www.fairtrading.qld.gov.au/consumer-product-related-injuries-in-Old-children.htm 